\title{
Cardiovascular Genomics
}

\section{A Current Overview of In Vivo and In Vitro Studies}

\author{
Devi Mariappan, * Johannes Winkler,* Jürgen Hescheler, and Agapios Sachinidis ${ }^{\dagger}$ \\ Center of Physiology and Pathophysiology Institute of Neurophysiology, Robert-Koch Strasse 39, \\ Cologne, Germany
}

${ }^{+}$Correspondence and reprint requests to:

Prof. Dr. A. Sachinidis

University of Cologne,

Center of Physiology

and Pathophysiology,

Institute of Neurophysiology,

Robert Koch Strasse 39,

Cologne, Germany.

E-mail: a.sachinidis@uni-koeln.de

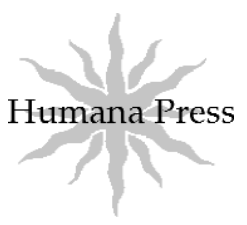

\begin{abstract}
The cardiovascular system is the first system that is developed in the embryo. The cardiovascular development is a complex process involving the coordination, differentiation, and interaction of distinct cell lineages to form the heart and the diverse array of arteries, veins, and capillaries required to supply oxygen and nutrients to all tissues. Embryonic stem cells have been proposed as an interesting model system to investigate molecular and cellular mechanisms involved in mammalian development. The present review is focused on extrinsic soluble factors, intrinsic transcription factors, receptors, signal transduction pathways, and genes regulating the development of cardiovascular system in vivo and in vitro. Special emphasis has been given to cardiovascular genomics including gene expression studies on the cardiovascular system under developmental and pathophysiological conditions.
\end{abstract}

Index Entries: Embryonic stemcells; cardiovascular genomics; cardiogenesis; angiogenesis; vasculogenesis.

\section{Introduction}

The heart is the first organ to form and function in the vertebrate embryo. Formation of the heart begins, when cells within bilaterally symmetrical regions of the anterior lateral plate mesoderm become committed to a cardiogenic fate in response to inductive signals from adjacent endoderm (reviewed in ref. 1). Cardiogenic precursor cells from this region, are known as the cardiac crescent that converge along the ventral midline of the embryo to form a beating linear heart tube made up of distinct myocardial and endocardial layers separated by an extracellular matrix. In all vertebrates, the linear heart tube undergoes rightward looping, which is essential for proper orientation of the pulmonary (right) and systemic (left) ventricles, and for alignment of the heart chambers with the vasculature. Analysis of the molecules and mechanisms involved in the specification of cardiac cell fates, differentiation and diversification of cardiac muscle cells, and patterning and morphogenesis of different cell types has revealed an evolutionarily conserved network of signaling pathways and transcription factors that underlies these processes (2). Embryonic stem (ES) cells have been proposed as an interesting model system to investigate molecular and cellular mechanisms involved in mammalian development $(3,4)$. ES cells are pluripotent cells derived from the inner cell mass of early blastocyst-stage embryos $(5,6)$. ES cells are maintained in the undifferentiated and pluripotent state by culturing them in the presence of leukaemia inhibitory factor and/or on feeder layers of mitotically inactivated embryonic fibroblasts. On leukaemia inhibitory factor removal, ES cells spontaneously undergo in vitro differentiation, either in monolayer or in aggregates (embryoid bodies), into all the 
derivatives of three primitive germ layers (7). In vitro studies with ES cell-derived-embryoid bodies have revealed a tightly regulated program of cardiomyogenesis that is triggered by specific signaling molecules and mediated by tissue-specific transcription factors $(8,9)$. This program involves the specification of cardiomyocytes from mesodermal stem cells and the subsequent activation of genes involved in cardiac force generation. During embryoid body differentiation toward functional cardiomyocytes, a number of transcription factors such as GATA-4, dHAND, eHAND, and Nkx2.5 play a critical role in early cardiac differentiation (8-10). Vascularization of organs and tissues proceeds by two related but distinct processes: vasculogenesis and angiogenesis (11). In vasculogenesis, primitive blood vessels develop from endothelial progenitor cells (angioblasts) - derivatives of embryonic and extraembryonic mesoderm, which differentiate and assemble into cord-like vascular structures that further organize into a primary vascular network. This process is involved in the development of the embryonic vascular system, including the dorsal aorta, the heart endocardium, and yolk sac $(12,13)$. Angiogenesis corresponds to the formation of new blood vessels from the pre-existing blood vasculature by the sprouting, splitting, and remodeling of the vascular network. In the adult, a neovascularization response occurs in a variety of physiological and pathological settings, including wound healing, recovery from myocardial infarction, inflammation-related diseases, solid tumor growth, and tumor metastasis. Although major progress has been made, molecular mechanisms involved in the regulation of both vasculogenic and angiogenic responses remain unclear. Therefore, there is a need for an in vitro model system that fully recapitulates spatio-temporal events involved during blood vessel formation.

\section{Transcription Factors Involved in Cardiogenesis \\ GATA Proteins}

The family of transcription factors are among the first to be expressed in the developing heart. The family consists of six members, GATA-1 through GATA-6, which is subdivided into two sub families based on sequence similarity and expression profiles. GATA-1, GATA-2, and GATA-3 are involved in haematopoiesis and ectodermal patterning, whereas GATA-4, GATA-5, and GATA-6 function in the formation of mesodermal and endodermal derivatives such as heart, liver, gut, and gonads $(14,15)$. A characteristic feature of GATA factors is the presence of two conserved zinc-finger motifs (referred to as $\mathrm{N}$-and C-terminal zinc fingers), containing the consensus amino acid sequence $\mathrm{Cys}_{2} \mathrm{Cys}_{2} \mathrm{C}_{17} \mathrm{Cys}_{2} \mathrm{Cys}(16)$. The zinc fingers mediate factor binding to the consensus DNA sequence (A/T)GATA(A/G) within target gene promoters and enhancers, as well as protein-protein interactions (14).

GATA-4 has been shown to be essential for cardiac differentiation in the embryonal carcinoma cell line P-19, a cell line induced to form beating cardiomyocytes by the addition of dimethylsulfoxide (DMSO) $(17,18)$. In mice, GATA-4 is one of the earliest transcription factors expressed in developing cardiac cells (19). Abundant levels of GATA-4 mRNA are present in both the endocardium and myocardium of the folding heart tube and GATA-4 continues to be expressed in cardiac myocytes throughout the life $(19,20)$. Targeted disruption of GATA-4 in transgenic mice results in embryonic lethality due to the failure to form a ventrally fused heart tube, thus indicating an important role of GATA-4 in transcriptional regulation during cardiac morphogenesis $(21,22)$. Moreover, overexpression of GATA-4 or GATA-6 in ES cells has been shown to induce differentiation toward extraembryonic endoderm (23). Functional knockout experiments with GATA-4 in mouse, GATA-5 in zebrafish, and simultaneous knockdown experiments with GATA-4 and GATA -6 in chick show early heart defects including the lack of fusion of the bilateral heart primordia (cardia bifida), decrease of $N k x 2.5$ expression, and a reduction in the number of cardiomyocytes expressing myocardial differentiation genes (21-25). Recent analyzes in chick using small interfering RNAs targeted to GATA-4 implicate the loss of $\mathrm{N}$-Cadherin as a potential cause of cardia bifida (26). In mouse, null mutations in GATA-5 cause no obvious cardiac defects, whereas in zebrafish a GATA-5 mutant has a cardia bifida phenotype similar to GATA-4 null mice (25). Interestingly, overexpression of GATA- 5 in zebrafish embryos leads not only to increased expression of Nkx2.5, GATA-4, and GATA-6, and myocardial genes in cardiac tissue, but also induced ectopic expression of some genes in noncardiac tissues. Likewise, overexpression of GATA-4 in ES cells shows enhanced cardiac differentiation (17). At present, the role of GATA- 6 has not been fully studied owing to the fact that GATA-6 -/- embryos die soon after implantation (27). Gain-of-function experiments in Xenopus embryos suggest a role of GATA-6 in cardiogenesis (28). More recent loss-of-function experiments in Xenopus and zebrafish, with the use of antisense morpholino oligonucleotides show for the first time that GATA-6 is required for differentiation of the cardiac lineage during embryogenesis (29). Several studies show that GATA-4 and Nkx2.5 directly interact at protein level to regulate the expression of cardiac-specific promoters, the atrial natriuretic factor, $\alpha$-cardiac actin and cardiac-restricted ankyrin repeat protein (CARP) (30).

\section{Homeodomain Proteins}

In Drosophila, the Nk-type homeobox gene tinman is the first regulatory gene known to be expressed in the precardiac mesoderm and to function in specifying cardiac precursors (31). Five tinman-related Nk-type homeobox genes, $N k x 2.3, N k x 2.5$, $N k x 2.6, N k x 2.7$, and $N k x 2.8$ are expressed in cardiac lineages in vertebrates (reviewed in ref. 32). The Csx (cardiac-specific homeobox) or $N k x 2.5$ is identified as a murine homolog to Drosophila tinman $(33,34)$. The homeodomain of Cs $x / N k x 2.5$ has a helix-turn-helix motif that binds to the specific consensus DNA sequence T(C/T)AAGTG (35). Targeted disruption of $N k \times 2.5$ in transgenic mice results in embryonic lethality owing to the abnormal heart morphogenesis and growth retardation (36). In these mice, the expression of $M L C-2 V$, the earliest known marker of ventricular differentiation is absent, whereas the expression of $\beta-M y H C$ and cyclin $\mathrm{D} 2$ remains normal. However, transgenic mice overexpressing Cs $x / N k x 2.5$ under the control of the cytomegalovirus enhancer/chicken $\beta$-actin promoter exhibit normal-sized hearts, but the expression levels of cardiac genes such as atrial natriuretic peptide, brain natriuretic peptide, $M L C-2 V$, and CARP are upregulated, whereas the expression level of GATA-4 remains unaltered (37). These gain-of-function studies suggest that $N k \times 2.5$ is not 
sufficient for the generation of cardiac hypertrophy but functions to control cardiac gene program in adult as well as in embryonic hearts. In mouse, the $N k x 2.6$ gene is expressed in addition to $N k x 2.5$ in the heart (38). The heart defects in the case of double mutant $N k x 2.5 / N k x 2.6$ embryos are only slightly more severe than those observed in single mutants $N k x 2.5$ (39). These results explain that there is only limited redundancy among $N k x 2$ genes in early cardiogenic tissue.

\section{MADS Box Genes}

The MADS (indicating MCM1, agamous, deficiens, and SRF) family of transcription factors share a conserved DNAbinding domain (MADS box). The targeted disruption of the serum response factor $(S R F)$ gene in mice reveal that this member of the MADS domain family of proteins is critical for the development of cardiac mesoderm (40). SRF physically interacts with GATA-4 or Nkx2.5 and results in strong transcriptional activation of the atrial natriuretic factor and $\alpha$-actin genes through a serum response element (30). SRF is negatively regulated by a small homeobox gene, Hop, which has a divergent homeodomain and is unable to bind to DNA $(41,42)$. The Nkx2.5 regulates the expression of Hop, and mice homozygous for a Hop null allele exhibit different phenotypes: some mutants develop early lethality owing to a deficiency in myocyte proliferation, whereas the majority of null mutants develop a hyperplastic heart postnatally. Therefore, Hop modulates SRF activity, which is important to balance signaling inputs that induces growth and differentiation in the myocardium.

The myocyte enhancer factor (MEF) 2 is another member of MADS box transcription factors, which binds to a conserved ATrich DNA sequence $\left[\mathrm{CAT}(\mathrm{A} / \mathrm{T})_{4} \mathrm{TAG} / \mathrm{A}\right]$ associated with most structural genes of cardiac muscle (43). They are expressed in cardiogenic precursor cells and differentiated cardiomyocytes during embryogenesis (44). In vertebrates, four MEF2 genes (MEF2- $A, M E F 2-B, M E F 2-C$, and MEF2-D) share homology in $\mathrm{NH}_{2}$-terminal MADS box and an adjacent motif known as the MEF2 domain (45). In mice, the four MEF2 genes are expressed in precursors of cardiac, skeletal, and smooth muscle lineages as well as in other cell types. A targeted mutation in the MEF2-C gene leads to arrested cardiac looping and right ventricular formation and downregulation of cardiac-specific genes similar to dHAND or Nkx2.5 mutants (46). In Drosophila, only a single MEF2 gene, DMEF2 is expressed in the precursor of myogenic lineages and their descendants. In DMEF2 null mutants, the early myogenic differentiation seems to be normal but correct myogenic differentiation of the heart does not occur $(47,48)$.

\section{Angiogenesis and Vasculogenesis}

The formation of the vascular network in the embryo is mediated by two distinct mechanisms, vasculogenesis and angiogenesis. The molecular regulation of these distinct mechanisms involves the most important positive regulators such as vascular endothelial growth factor (VEGF) and its receptors, and the angiopoietin/Tie system. Intense investigation into the molecular mechanisms of angiogenesis has identified novel signaling pathways involved in the generation of new vasculature. These insights range from elucidation of the mechanism, by which hypoxia initiates expression of a proangiogenic gene repertoire through the hypoxia-inducible transcription factors to molecular pathways involved in extra- and intracellular signaling during new vessel formation. Extracellular pathways include the Ephrin/Eph receptor, Notch/delta and roundabout/slit families, and intracellular pathway members of hedgehog and sprouty families (49).

\section{Vascular Endothelial Growth Factor}

VEGF is a key regulator of physiological angiogenesis during embryogenesis, skeletal growth, and reproductive functions. VEGF has also been implicated in pathological angiogenesis associated with tumors and intraocular neovascular syndromes. The VEGF family consists several members including VEGF, placenta growth factor (PlGF), VEGF-B, VEGF-C, VEGF-D, and Orf virus VEGFs (also called VEGF-E) (50-52). Three receptors for the VEGFs have been identified. In adults, VEGFR-1 (flt-1) and VEGFR-2 (KDR/flk-1) are mainly expressed in the blood vascular endothelium, whereas VEGFR-3 (flt-4) is highly restricted to the lymphatic endothelium (53-57). VEGF receptors belong to the "7-Ig" or flt family, a gene family characterized by seven extracellular immunoglobulin-like domains, one membrane-spanning segment, and a conserved intracellular tyrosine domain $(58,59)$. In human, alternative exon splicing of a single gene results in the generation of six isoforms of VEGF made up of 121, 145, 165, 183, 189, and 206 amino acids, respectively, among which $\mathrm{VEGF}_{165}$ is the predominantly expressed isoform $(54,60,61)$. These isoforms differ primarily in heparin binding, which might affect their diffusion rates in the extracellular matrix. VEGF (also called VEGF-A) binds two related receptor tyrosine kinases (RTKs), VEGFR-1 and VEGFR-2. The VEGFR-3, a member of the same RTK family does not bind VEGF, but rather complexes VEGF-related proteins VEGF-C and VEGF-D. Recently neuropilin-1 (NRP-1), a cell surface glycoprotein that acts as a receptor for collapsins/semaphorins, which is implicated in axonal guidance, has been identified as an isoform-specific receptor for VEGF ${ }_{165}$, PlGF-2, VEGF-B, and Orf virus VEGFs (62-65).

Disruption of VEGF or either of its two receptors VEGFR-1 and VEGFR-2 results in early embryonic lethality because of a failure of blood vessel development $(51,52,66)$. VEGF plays an important role also in early postnatal life (67). Partial inhibition of VEGF achieved by Cre-loxp-mediated gene targeting results in increased mortality, stunted body growth, and impaired organ development. In mouse embryos with targeted null mutations of VEGFR-2, differentiation of both endothelial and haematopoietic cells are blocked, resulting in a complete failure of vasculogenesis (68). Targeted inactivation of the gene encoding VEGFR-3 leads to a defect in remodeling of the primary vascular plexus and cardiovascular failure at embryonic day 9.5 (69). This result suggests that VEGFR-3 signaling is necessary for the development of the embryonic cardiovascular system. Other VEGF-binding proteins, such as NRP-1 seem to be involved in the regulation of angiogenesis during development. NRP-1 overexpression in mice results in the formation of a high density of dilated blood vessels and death in utero (70). Furthermore, NRP-1 deficient mice exhibit disrupted blood vessels and insufficient development of vascular networks (71).

\section{Angiopoietin/Tie Receptors}

Four members of the angiopoietin family have been identified to date that binds Tie family receptors. Angiopoietins and Tie receptor have been reported to play an important role in 
angiogenesis. Interestingly, these ligands appear to have opposing actions in endothelial cells as angiopoietin (Ang)- 1 and Ang-4 induce tyrosine phosphorylation of Tie-2, whereas Ang-2 and Ang-3 inhibit this phosphorylation (72-75). Additionally, Ang-1 is chemotactic for endothelial cells, but does not cause endothelial cell proliferation or tube formation in vitro $(72,76)$. Targeted gene inactivation of Ang-1 causes embryonic lethality owing to the defective modeling of primitive vascular plexus and lack of perivascular cells, similar to Tie-2 knockout mice (77). The most severe defects are in the heart, where endocardial and trabecular development is notably impaired. The heart trabeculation phenotype indicates that Ang- 1 and Tie-2 are involved in the recruitment of perivascular cells and is required for the maturation of blood vessels during embryonic development. Overexpression of Ang-1 in transgenic mice induces numerous highly branched and enlarged blood vessels compared with wild-type mice (78). Moreover, Ang-1 also stimulates the formation of endothelial cell sprouts in vitro, and it acts synergistically with VEGF in this assay (79). Therefore, it is likely that Ang-1 and VEGF cooperate to stimulate capillaries sprouting in the developing organisms.

Ang-2 has a $60 \%$ structural homology to Ang-1. Therefore, Ang-2 acts as an antagonist of Tie-2 through inhibition of Ang-1-induced phosphorylation of Tie-2. Mice that overexpress the Ang-2 ligand exhibit a phenotype similar to those observed in Tie-2 or Ang-1-deficient mice (73). Therefore, Ang-2 antagonises Ang-1 in the vasculature in vivo, thus preventing excessive branching and sprouting of blood vessels by promoting destabilization of blood vessels.

One type of RTK is the tyrosine with immunoglobulin and epidermal growth factor homology domains (Tie) receptors $(80,81)$. Tie-2/Tek is expressed predominantly on endothelial cells, haematopoietic cells, or their embryonic precursors and it is required for normal vascular development (82). Functional disruption of Tie- 2 in transgenic mice results in early embryonic lethality, with effects on the microvasculature resulting in reduced number of endothelial cells, and abnormalities of vascular morphogenesis and haematopoiesis (82). Thus, Tie-2 is critical for angiogenesis and haematopoiesis during development.

\section{Eph/Ephrin}

Eph receptors belong to the largest known family of RTKs consisting of at least 14 membrane-bound proteins, and eight transmembraneligands (ephrins) have been identified (83). Their expression is not restricted to endothelium, but widely expressed in many embryonic and adult tissues. The ephrin ligands are divided into A and B type molecules based on their localization in the plasma membrane. Several Ephrins and Eph receptors have been shown to be present directly on the vascular endothelium, among which ephrin A1, appears to play a role in the inflammatory angiogenesis stimulated by tumor necrosis factor (TNF)- $\alpha$ (84), and ephrin B1, promotes endothelial capillarylike assembly and attachment in vivo (85). Ephrin B2 and the Eph receptors Eph B3 and Eph B4 are also known to be present in vascular endothelium. Interesting studies on mice lacking Ephrin B2 and eph B4 highlighted defects on early on early angiogenic remodeling comparable with the Ang-1- or Tie-2deficient mouse (86-88). Ephrin B2 expression continues to mark arteries during later embryonic development and in the adult, underlying that it might be involved in the regulating interactions of endothelial and smooth muscle cells implicated in the formation of arterial muscle walls.

\section{Notch/Delta}

Notch signaling is an evolutionarily conserved intercellular signaling pathway that plays a key role in embryonic vascular development and angiogenesis. Four notch receptors (Notch1-4) and five DSL (named for Delta and serrate from Drosophila and Lag-2 from Caenorhabditis elegans) ligands (jagged1 and 2, delta-like1 (DLL1, DLL3, and DLL4) have been described in mammals (89). All the receptors and ligands are expressed in at least one vascular compartment, for example, arteries, veins, capillaries, and vascular smooth muscle cells or pericytes. However, the expression of Notch 4 is specific to arterial blood vessels (90), whereas the other receptors are widely expressed in several cell types and tissues. Similarly, the ligand DLL4 is endothelial specific $(91,92)$. In human, mutations in jagged 1 and Notch3 genes cause the autosomaldominant disorders, Alagille's syndrome and CADASIL (Cerebral autosomal-dominant arteriopathy with subcortical infarcts and leukoencephalopathy), respectively, and both display abnormal vascular phenotypes (93). Haploinsufficiency of DLL4 results in embryonic lethality in mice owing to severe vascular defects (94). The only other angiogenic pathway, for which haploinsufficiency is reported is for VEGF knockout mice. Activation of the Notch pathway by jagged1, N1ICD, and N4ICD inhibited proliferation of human umbilical vein endothelial cells (HUVECs) and human aortic endothelial cells (HAECs) (95), whereas jagged 1 was able to induce microvessel-like structures in vitro. Overexpression of the dominant-negative form of jagged1 (sjag1) in HUVEC inhibited the endothelial network formation. However, addition of a jagged 1 oligonucleotide to bovine microvascular endothelial cells increased invasion and tube formation during fibroblast growth factor-induced angiogenesis. Thus, although Notch has critical roles in vivo in the embryonic vascular development, in vitro it appears that function of the notch pathway in endothelial cells is dependent on the endothelial type and activation of notch signaling is likely to inhibit endothelial proliferation.

\section{Sprouty and Angiogenesis}

Sprouty (Spry) was first identified in Drosophila as a novel antagonist of the fibroblast growth factor signaling during tracheal development. In Drosophila, sprouty is expressed at the apical branches of the tracheal system, in the eye imaginal disk, the embryonic chordotonal organ precursors and in midline glia (96-98). The sprouty proteins define a new family of putative signaling modulators. Up to now, one Drosophila, one Xenopus, one avian (chick Spry2), three mouse isoforms (mSpry1,2, and 4) and four human sprouty isoforms (hSpry1-4) have been identified. Sprouty proteins have a highly conserved C-terminal cysteine-rich domain which confers inhibitory activity and a variable $\mathrm{N}$-terminal region responsible for functional divergence $(99,100)$. Mouse homologs of sprouty (mSpry1, 2, and 4) are expressed in embryonic and adult tissues such as brain, heart, kidney, lung, limbs, and skeletal muscle (101-103). Inhibition of murine Spry2 by antisense oligonucleotides enhances terminal branching of cultured mouse lungs suggesting that sprouty proteins negatively 
modulate branching morphogenesis in the Drosophila and mouse respiratory systems (103). Direct evidence for the role of sprouty proteins comes from a study where the mouse Spry 4 was overexpressed in the developing endothelium of the mouse embryo using an adenoviral vector (104). It has been reported that in the embryos overexpressing mSpry4, formation of a network of small and larger vessels and sprouting from existing vessels are disrupted. By whole-mount PECAM staining, it was found that there was disorganized and primitive vascular network in the head, heart, and intersomatic vessels, which clearly indicates that sprouty inhibits branching and sprouting of the vasculature during angiogenesis. It was also observed that overexpression of Spry4 inhibited mitogen-activated protein kinase activation induced by bFGF or VEGF.

\section{Roundabouts and Slits}

Roundabout was originally isolated from Drosophila (105), but other family members were rapidly identified from species including C. elegans, zebrafish, mouse, and human (106-108). Roundabouts are large transmembrane receptor proteins with an extracellular domain made up of five immunoglobulin and three fibronectin motifs followed by a long cytoplasmic tail. The roundabout cognate ligands are the slits, of which three are known in human (109-112). The slits and roundabouts are involved in axon guidance and neuronal migration, where they mediate a repulsive signal $(105,109)$. A computational data mining procedure was used to identify a novel, endothelialspecific gene named as magic roundabout ( $\mathrm{ROBO} 4$ ), which showed homology to the axon guidance protein roundabout (ROBO1); (113). These studies suggest that ROBO4 expression in vitro was detected in endothelial cells and an increased expression was observed in cells exposed to hypoxia. In situ hybridization reveals that the expression of $\mathrm{ROBO} 4$ in the adult was restricted exclusively to sites of active angiogenesis, notably tumor vessels. Recently, a soluble chimeric receptor (Robo4fc) including of the Robo4 extracellular domain fused to the fc region of immunoglobulin has been reported to inhibit endothelial cell migration and angiogenesis in vivo (114). The identity of the Robo4 ligand and the mechanism of Robofc action remain to be determined.

\section{Genomic Analyses}

Global gene expression analysis is becoming an important tool to investigate the candidate genes involved in cardiovascular diseases. Cardiovascular diseases like atherosclerosis, coronary artery diseases, hypertension, and stroke, which are genetically complex, involves an interplay of many genetic variations of molecular and biochemical pathways and their interactions with environmental factors. However, the key regulators involved in the onset of diseases remain unidentified. Genomic research has broadened our knowledge in understanding the aspects of cardiovascular function, including molecular signaling, contractile mechanisms and energetics, vascular and myocardial structure and remodeling, and electrical activation and propagation. In recent years, several methods allowing simultaneous analysis of the expression of hundreds to thousands of genes have been developed. Among various methods, microarray hybridization techniques and serial analysis of gene expression (SAGE) have been widely used for studying cardiovascular diseases, which are discussed later.

\section{Serial Analysis of Gene Expression}

SAGE is one of the most powerful tools available for global expression profiling at the mRNA level. SAGE analysis relies on two basic principles: (1) short nucleotide sequences (10-14 bp) are sufficient to identify a transcript and (2) short nucleotide sequences or tags are concatenated (linked together) allowing rapid sequencing of multiple transcripts per sequencing reaction (115). This approach allows the identification of novel sequences and thus stimulates further work for the characterization of new transcripts. The SAGE technique has been successfully used for identifying cell-cycle regulation, apoptosis, and tumor-specific marker genes (116-119). In the field of cardiovascular biology, SAGE technique is useful in several areas, which include stem cell biology, cardiovascular development, angiogenesis, atherosclerosis, and lipid regulation. SAGE analysis has been used to define the transcriptomes of P19EC and R1 ES cell lines $(120,121)$. New targets in tumor endothelium have been identified by comparing gene libraries constructed from isolated endothelial cells from tumors and normal tissue using SAGE (118). SAGE studies have also been reported for human hematopoietic stem cells, hyperlipidemic ApoE3Leiden mice and endothelial cells exposed to atherogenic stimulus (122-124). In the future, SAGE could also assist in finding new targets of important transcription factors such as $N k x 2.5$ in cardiogenesis, where the number of cells might be limited. Also the establishment of an electronic database of cardiovascular SAGE libraries might facilitate efficient data mining by researchers provide new insights in the future. Ultimately, the true measure of success of cardiovascular gene expression studies will be the impact of their discovery on helping focus research on the development of new diagnostic, prognostic and therapeutic tools for the prevention and treatment of cardiovascular diseases in patients.

\section{Microarrays \\ Complementary DNA Microarrays}

For Complementary DNA (cDNA) microarrays, thousands of cDNA clones are individually amplified by PCR and spotted on a solid support, usually on glass slides. cDNA from cells is synthesized using mRNAs from two samples (e.g., control and treated) and labeled with Cy3 and Cy5 fluorescent dyes, respectively. The labeled cDNAs are pooled and hybridized to the same array and scanned for fluorescence with two different excitation wavelengths. Fluorescence intensity data are then analyzed to yield log-transformed ratios between Cy3 and Cy5 in each spot, which, with spotted DNA probes in excess, reflect the relative mRNA expression levels of the corresponding gene in the control and treated samples. For example, genes equally expressed in both control and treated samples will fluoresce with both colors digitally portrayed as yellow. When compared with oligonucleotide arrays, cDNA arrays eliminate the need for the probe design required for oligonucleotide array and also allow the entire genome of the organism to be represented on the array easily, which makes it useful for the analysis of gene expression.

\section{Oligonucleotide Microarrays}

Oligonucleotide microarrays are extremely powerful in large-scale studies of gene expression. This technique uses 
short sequences ( $25 \mathrm{bp}$ ) of DNA to be synthesized as an array. Typically, a transcript of interest (usually related to a gene) is represented by a probe set made up of 11-20 probe pairs of these oligonucleotides. Each probe pair is made up of a perfect match probe, a section of the mRNA molecule of interest, and a mismatch probe, in which the central nucleotide is mutated with the intention of measuring nonspecific binding. The hybridized arrays are then scanned and the results are digitally recorded and are expressed as units of fluorescence intensity. Analysis of the data thus generated demonstrates the patterns of the up- and downregulation of genes and makes possible the identification of signaling networks and diseaserelated modifications. Comparing these patterns and extracting groups of genes with similar expression profiles might suggest roles for uncharacterized transcripts. Also the expression profiles of many genes, when taken together, allow a more accurate and specific classification of diseases. Oligonucleotide arrays possess advantages such as greater hybridization specificity owing to their perfect match/mismatch probe design. This combined with their more specific fluorescence detection (as there are multiple oligonucleotides representing each gene to be studied) make oligonucleotide arrays one of the most powerful techniques for monitoring expression levels of a differentially spliced transcript. However, both cDNA and oligonucleotide arrays are limited by the number of known genes and do not permit the discovery of novel genes.

Numerous investigators have used microarrays and other large-scale profiling technologies such as subtractive hybridization $(125,126)$ or genecalling $(127)$ to elucidate transcriptional profiles in experimental models of myocardial infarction (128-131), myocarditis (132) and various ventricular hypertrophy models (133-135).

The number of genes expressed in the cardiovascular system has been estimated to be between 21,000 and 27,000 (136), and cardiovascular-based cDNAarrays (CardioChips) have been developed as described previously (137) to facilitate the identification of cardiac-specific genetic markers (130-132,137). Using cDNA microarrays, differential gene expression patterns have been identified after myocardial infarction in rodent rat $(128,130,131)$ and mouse models $(129)$. These studies support and complement each other, offering a comprehensive view of the modifications in gene expression that take place in the infarcted cardiac tissue. Upregulation of extracellular matrix genes (including collagens, fibronectin, and osteopontins) is a common finding that accounts for the observed abundance of extracellular matrix proteins. Some actin assembly-regulating proteins such as thymosins, moesin, Arp2/3 are also upregulated, whereas muscle contractile proteins ( $\alpha$-cardiac myosin heavy chain, atrial myosin light chain) are either up- or downregulated (titin, tropomyosin 4, troponin I, and so on) (138). Several ribosomal proteins and transcription factors, including Egr-1, are upregulated. Atrial natriuretic peptide and brain natriuretic peptide are also increased.

At the cellular level, differential gene expression studies have defined novel endothelial signaling pathways (139) and chemotactic pathways that might participate in atherosclerosis (140). Atherosclerosis is a multifactorial, progressive disease of the large arteries (141), and its most prominent features are the accumulation of subendothelial deposits of lipids, fibrous material, and cell debris. The accumulating cells are either macrophages or smooth muscle cells. These cells take up cholesterol and other lipids, which form lipid droplets, eventually filling the cell. This accumulation gives them a foamy appearance and hence the name foam cells. A large number of risk factors, both genetic and environmental, have been described during the last half century. In addition to molecular epidemiological approaches to identify genes that determine atherosclerosis susceptibility, differential gene expression analysis at different stages of human and animal atherosclerosis progression and in different regions of the vasculature will provide an important insight into the development of this disorder (142). High throughput screening combined with bioinformatical analysis has played a role in the identification of a second angiotensin-converting enzyme gene (ACE2), whose protein product is not inhibited by lisinopril or captopril (143). ACE2 is predominantly expressed in the endothelium and in the renal epithelium, and it might be an important new cardiovascular target.

DNA microarrys have also been applied to gene expression in single endothelial cells, providing insight into cell-to-cell genomic variation (144). Smad7, which inhibits the formation of transforming growth factor- $\beta$-dependent Smad2/Smad4 complexes (145), represents a potential new endothelial target for preventing atherosclerosis. As microarray technology and data analysis/mining capabilities constantly improve, it can be foreseen that microarrays will complement currently used methods in diagnosis, prognostic prediction, and therapeutic decision making in the future.

\section{Acknowledgment}

This work was supported by a grant from the European Community (6th Framework Programme, Thematic Priority: Life sciences, genomics and biotechnology for health, Contract No: FunGenES LSHG-CT-2003-503494).

\section{References}

1 Nascone N, Mercola M. Trends in Cardiovasc Med 1996;6: 211-216.

2 Cripps RM, Olson EN. Dev Biol 2002;246:14-28.

3 Gissel C, Voolstra C, Doss MX, et al. Thromb Haemost 2005;94: 719-727.

4 Rathjen PD, Lake J, Whyatt LM, Bettess MD, Rathjen J. Reprod Fertil Dev 1998;10:31-47.

5 Odorico JS, Kaufman DS, Thomson JA. Stem Cells 2001; 19:193-204.

6 Thomson JA, Itskovitz-Eldor J, Shapiro SS, et al. Science 2001;282: 1145-1147.

7 Smith AG. Semin Cell Biol 1992;3:385-399.

8 Sachinidis A, Fleischmann BK, Kolossov E, Wartenberg M, Sauer H, Hescheler J. Cardiovasc Res 2003;58:278-291.

9 Winkler J, Hescheler J, Sachinidis A. Biochim Biophys Acta 2005;1740(2):240-248.

10 Czyz J, Wobus A. Differentiation 2001;68:167-174.

11 Risau W. Nature 1997;386:671-674.

12 Coffin JD, Harrison J, Schwartz S, Heimark R. Dev Biol 1991; 148:51-62.

13 Pardanaud L, Altmann C, Kitos P, Dieterlen-Lievre F, Buck CA. Development 1987;100:339-349.

14 Molkentin JD. J Biol Chem 2000;275:38,949-38,952.

15 Patient RK, McGhee JD. Curr Opin Genet Dev 2002;12:416-422.

16 Evans T, Felsenfeld G. Cell 1989;58:877-885.

17 Grepin C, Nemer G, Nemer M. Development 1997;124: 2387-2395.

18 Grepin C, Robitaille L, Antakly T, Nemer M. Mol Cell Biol 1995; 15:4095-4102.

- Volume 2, 2006 
19 Heikinheimo M, Scandrett JM, Wilson DB. Dev Biol 1994; 164:361-373.

20 Arceci RJ, King AA, Simon MC, Orkin SH, Wilson DB. Mol Cell Biol 1993;13:2235-2246.

21 Kuo CT, Morrisey EE, Anandappa R, et al. Genes Dev 1997;11: 1048-1060.

22 Molkentin JD, Lin Q, Duncan SA, Olson EN. Genes Dev 1997;11: 1061-1072.

23 Fujikura J, Yamato E, Yonemura S, et al. Genes Dev 2002;16: 784-789.

24 Jiang Y, TarzamiS, Burch JB, Evans T. Dev Genet 1998;22:263-277.

25 Reiter JF, Alexander J, Rodaway A, et al. Genes Dev 1999;13: 2983-2995.

26 Zhang H, Toyofuku T, Kamei J, Hori M. Biochem Biophys Res Commun 2003;312:1033-1038.

27 Morrisey EE, Tang Z, Sigrist K, et al. Genes Dev 1998;12: 3579-3590.

28 Gove C, Walmsley M, Nijjar S, et al. EMBO J 1997;16:355-368.

29 Peterkin T, Gibson A, Patient R. EMBO J 2003;22:4260-4273.

30 McBride K, Nemer M. Can J Physiol Pharmacol 2001;79:673-681.

31 Zaffran S, Frasch M. Circ Res 2002;91:457-469.

32 Harvey RP. Dev Biol 1996;178:203-216.

33 Komuro I, Izumo S. Proc Nat Acad Sci USA 1993;90:8145-8149.

34 Lints TJ, Parsons LM, Hartley L, Lyons I, Harvey RP. Development 1993;119:419-431.

35 Chen CY, Schwartz RJ. J Biol Chem 1995;270:15,628-15,633.

36 Lyons I, Parsons LM, Hartley L, et al. Genes Dev 1995;9: 1654-1666.

37 Takimoto E, Mizuno T, Terasaki F. Biochem Biophys Res Commun 2000;270:1074-1079.

38 Tanaka M, Yamasaki N, Izumo S. Mol Cell Biol 2000;20: 2874-2879.

39 Tanaka M, Schinke M, Liao HS, Yamasaki N, Izumo S. Mol Cell Biol 2001;21:4391-4398.

40 Arsenian S, Weinhold B, Oelgeschlager M, Ruther U, Nordheim A. EMBO J 1998;17:6289-6299.

41 Chen F, Kook H, Milewski R, et al. Cell 2002;110:713-723.

42 Shin CH, Liu ZP, Passier R, et al. Cell 2002;110:725-735.

43 Gossett LA, Kelvin DJ, Sternberg EA, Olson EN. Mol Cell Biol 1989;9:5022-5033.

44 Edmondson DG, Lyons GE, Martin JF, Olson EN. Development 1994;120:1251-1263.

45 Olson EN, Perry M, Schulz RA. Dev Biol 1995;172:2-14.

46 Lin Q, Schwarz J, Bucana C, Olson EN. Science 1997;276: 1404-1407.

47 Bour BA, O'Brien MA, Lockwood WL, et al. Genes Dev 1995;9: 730-741.

48 Lilly B, Zhao B, Ranganayakulu G, Paterson BM, Schulz RA, Olson EN. Science 1995;267:688-693.

49 Bicknell R, Harris AL. Annu Rev Pharmacol Toxicol 2004;44:219-238.

50 Ferrara N. Kidney Int 1999;56:794-814.

51 Ferrara N, Davis-Smyth T. Endocr Rev 1997;18:4-25.

52 Korpelainen EI, Alitalo K. Curr Opin Cell Biol 1998;10:159-164.

53 Aprelikova O, Pajusola K, Partanen J, et al. Cancer Res 1992;52:746-748

54 Neufeld G, Cohen T, Gengrinovitch S, Poltorak Z. Faseb J 1999;13:9-22.

55 Shibuya M, Ito N, Claesson-Welsh L. Curr Top Microbiol Immunol 1999;237:59-83.

56 Shibuya M, Yamaguchi S, Yamane A, et al. Oncogene 1990;5:519-524.

57 Terman BI, Carrion ME, Kovacs E, Rasmussen BA, Eddy RL, Shows TB. Oncogene 1991; 6:1677-1683.

58 Quinn TP, Peters KG, De Vries C, Ferrara N, Williams LT. Proc Nat Acad Sci USA 1993;90:7533-7537.

59 Sawano A, Iwai S, Sakurai Y, et al. Blood 2001:97:785-791.

60 Houck KA, Ferrara N, Winer J, Cachianes G, Li B, Leung DW. Mol Endocrinol 1991;5:1806-1814.
61 Tischer E, Mitchell R, Hartman T, et al. J Biol Chem 1991;266: 11,947-11,954.

62 Makinen T, Olofsson B, Karpanen T, et al. J Biol Chem 1999;274: 21,217-21,222.

63 Migdal M, Huppertz B, Tessler S, et al. J Biol Chem 1998;273:22,272-22,278.

64 Soker S, Takashima S, Miao HQ, Neufeld G, Klagsbrun M. Cell 1998;92:735-745.

65 Wise LM, Veikkola T, Mercer AA, et al. Proc Nat Acad Sci USA 1999;96:3071-3076.

66 Carmeliet P, Ferreira V, Breier G, et al. Nature 1996;380:435-439.

67 Gerber HP, Hillan KJ, Ryan AM, et al. Development 1999;126: 1149-1159.

68 Shalaby F, Rossant J, Yamaguchi TP, et al. Nature 1995;376:62-66.

69 Dumont DJ, Jussila L, Taipale J, et al. Science 1998;282:946-949.

70 Kitsukawa T, Shimono A, Kawakami A, Kondoh H, Fujisawa H. Development 1995;121:4309-4318.

71 Kawasaki T, Kitsukawa T, Bekku Y, et al. Development 1999:126:4895-4902.

72 Davis S, Aldrich TH, Jones PF, et al. Cell 1996;87:1161-1169.

73 Maisonpierre PC, Suri C, Jones PF, et al. Science 1997;277:55-60.

74 Mezquita J, Mezquita B, Pau M, Mezquita C. Biochem Biophys Res Commun 1999;260:492-498.

75 Valenzuela DM, Griffiths JA, Rojas J, Proc Nat Acad Sci USA 1999;96:1904-1909.

76 Witzenbichler B, Maisonpierre PC, Jones P, Yancopoulos GD, Isner JM. J Biol Chem 1998;273:18,514-18,521.

77 Suri C, Jones PF, Patan S, et al. Cell 1996;87:1171-1180.

78 Suri C, McClain J, Thurston G, et al. Science 1998;282:468-471.

79 Koblizek TI, Weiss C, Yancopoulos GD, Deutsch U, Risau W. Curr Biol 1998;8:529-532.

80 Dumont DJ, Gradwohl GJ, Fong GH, Auerbach R, Breitman ML. Oncogene 1993;8:1293-1301.

81 Mustonen T, Alitalo K. J Cell Biol 1995;129:895-898.

82 Sato TN, Tozawa Y, Deutsch U, et al. Nature 1995;376:70-74.

83 Yancopoulos GD, Davis S, Gale NW, Rudge JS, Wiegand SJ, Holash J. Nature 2000;407:242-248.

84 Pandey A, Shao H, Marks RM, Polverini PJ, Dixit VM. Science 1995;268:567-569.

85 Stein E, Lane AA, Cerretti DP, et al. Genes Dev 1998;12:667-678.

86 Adams RH, Wilkinson GA, Weiss C, et al. Genes Dev 1999;13: 295-306.

87 Gerety SS, Wang HU, Chen ZF, Anderson DJ. Mol Cell 1999;4: 403-414

88 Wang HU, Chen ZF, Anderson DJ. Cell 1998;93:741-753.

89 Iso T, Hamamori Y, Kedes L. Arterioscler Thromb Vasc Biol 2003;23:543-553.

90 Uyttendaele H, Ho J, Rossant J, Kitajewski J. Proc Nat Acad Sci USA 2001;98:5643-5648

91 Mailhos C, Modlich U, Lewis J, Harris A, Bicknell R, IshHorowicz D. Differentiation 2001;69:135-144.

92 Shutter JR, Scully S, Fan W, et al. Genes Dev 2000;14:1313-1318.

93 Kalaria RN, Low WC, Oakley AE, et al. J Neural Transm Suppl 2002;63:75-90.

94 Gale NW, Dominguez MG, Noguera I, et al. Proc Nat Acad Sci USA 2004;101:15,949-15,954

95 Noseda M, Chang L, McLean G, et al. Mol Cell Biol 2004:24:8813-8822.

96 Casci T, Vinos J, Freeman M. Cell 1999;96:655-665.

97 Hacohen N, Kramer S, Sutherland D, Hiromi Y, Krasnow MA. Cell 1998;92:253-263.

98 Kramer S, Okabe M, Hacohen N, Krasnow MA, Hiromi Y. Development 1999;126:2515-2525.

99 Egan JE, Hall AB, Yatsula BA, Bar-Sagi D. Proc Nat Acad Sci USA 2002:99:6041-6046.

100 Yigzaw Y, Cartin L, Pierre S, Scholich K, Patel TB. J Biol Chem $2001 ; 276: 22,742-22,747$

101 de Maximy AA, Nakatake Y, Moncada S, Itoh N, Thiery JP, Bellusci S. Mech Dev 1999;81:213-216. 
102 Minowada G, Jarvis LA, Chi CL, et al. Development 1999;126: $4465-4475$.

103 Tefft JD, Lee M, Smith S, et al. Curr Biol 1999;9:219-222.

104 LeeSH, Schloss DJ, Jarvis L, Krasnow MA, Swain JL. J Biol Chem 2001;276:4128-4133.

105 Kidd T, Brose K, Mitchell KJ, et al. Cell 1998;92:205-215.

106 Lee JS, Ray R, Chien CB. Dev Dyn 2001;221:216-230.

107 Yuan SS, Cox LA, Dasika GK, Lee EY. Dev Biol 1999;207:62-75.

108 Zallen JA, Yi BA, Bargmann CI. Cell 1998;92:217-227.

109 Brose K, Bland KS, Wang KH, et al. Cell 1999;96:795-806.

110 Itoh A, Miyabayashi T, Ohno M, Sakano S. Brain Res Mol Brain Res 1998;62:175-186.

111 Kidd T, Bland KS, Goodman CS. Cell 1999;96:785-794

112 Nakayama M, Nakajima D, Nagase T, Nomura N, Seki N, Ohara O. Genomics 1998;51:27-34

113 Huminiecki L, Gorn M, Suchting S, Poulsom R, Bicknell R. Genomics 2002;79:547-552.

114 Suchting S, Heal P, Tahtis K, Stewart LM, Bicknell R. Faseb J 2005;19:121-123.

115 Velculescu VE, Zhang L, Vogelstein B, Kinzler KW. Science 1995;270:484-487.

116 He TC, Sparks AB, Rago C, et al. Science 1998;281:1509-1512.

117 Hwang PM, Bunz F, Yu J, et al. Nat Med 2001;7:1111-1117.

118 StCroix B, Rago C, Velculescu V, etal. Science 2000;289:1197-1202.

119 Yu J, Zhang L, Hwang PM, Kinzler KW, Vogelstein B. Mol Cell 2001;7:673-682.

120 Anisimov SV, Tarasov KV, Riordon D, Wobus AM, Boheler KR. Mech Dev 2002;117:25-74

121 Anisimov SV, Tarasov KV, Tweedie D, Stern MD, Wobus AM, Boheler KR.Genomics 2002;79:169-176.

122 de Waard V, van den Berg BM, Veken J, Schultz-Heienbrok R, Pannekoek H, van Zonneveld AJ. Gene 1999;226:1-8.

123 Kreeft AJ, Moen CJ, Hofker MH, et al. Arterioscler Thromb Vasc Biol 2001;21:1984-1990.
124 Zhou G, Chen J, Lee S, Clark T, Rowley JD, Wang SM. Proc Nat Acad Sci USA 2001;98:13,966-13,971.

125 Depre C, Tomlinson JE, Kudej RK, et al. Proc Nat Acad Sci USA 2001;98:9336-9341.

126 Johnatty SE, Dyck JR, Michael LH, Olson EN, Abdellatif MJ Mol Cell Cardiol 2000;32:805-815.

127 Shimkets RA, Lowe DG, Tai JT, et al. Nat Biotechnol 1999;17:798-803.

128 Jin H, Yang R, Awad TA, et al. Circulation 2001;103:736-742.

129 Lyn D, Liu X, Bennett NA, Emmett NL. Physiol Genomics 2000;2:93-100.

130 Sehl PD, Tai JT, Hillan KJ, et al. Circulation 2000;101:1990-1999.

131 Stanton LW, Garrard LJ, Damm D, et al. Circ Res 2000;86:939-945.

132 Taylor LA, Carthy CM, Yang D, et al. Circ Res 2000;87:328-334.

133. Aronow BJ, Toyokawa T, Canning A, et al. 2nd Physiol Genomics 2001;6:19-28.

134. Friddle CJ, Koga T, Rubin EM, Bristow J. Proc Nat Acad Sci USA 2000;97:6745-6750

135 Liu T, LaiH, Wu W, ChinnS, Wang PH.Circ Res 2001;88:1231-1238.

136 Dempsey AA, Dzau VJ, Liew CC. J Mol Cell Cardiol 2001;33: 1879-1886.

137 Barrans JD, Stamatiou D, Liew C. Biochem Biophys Res Commun 2001;280:964-969.

138 Moldovan L, Moldovan NI. Arch Pathol Lab Med 2002;126: 310-316.

139 Topper JN, Cai J, Qiu Y, et al. Proc Nat Acad Sci USA 1997;94: 9314-9319.

140 Haley KJ, Lilly CM, Yang JH, etal. Circulation 2000;102:2185-2189.

141 Lusis AJ. Nature 2000;407:233-241.

142 Rubin EM, Tall A. Nature 2000;407:265-269.

143 Donoghue M, Hsieh F, Baronas E, et al. Circ Res 2000;87:E1-E9.

144. Davies PF, Polacek DC, Handen JS, Helmke BP, DePaola N. Trends Biotechnol 1999;17:347-351.

145. Hayashi H, Abdollah S, Qiu Y, et al. Cell 1997;89:1165-1173. 